WALKER, J. F. C. and R. NAKADA (1999): Understanding corewood in some softwoods: a selective review on stiffness and acoustics. Int. For. Rev. 1: 251-259.

Xiping, W., R. J. Ross, J. R. ERICKSON, J. W. Forsman, M. McClellan, R. J. Barbour and R. F. Pellerin (2000): Nondestructive evaluation of standing trees with stress wave methods. In: Proceedings of the $12^{\text {th }}$ International Symposium on Nondestructive Testing of Wood, Hungary. Edited by F. Divos and R. F. PELLERIN. University of Western Hungary, Sopron. pp. 197-206.

\title{
Estimating Genetic Parameters for Wood Density of Scots Pine (Pinus sylvestris L.)
}

\author{
By A. FrIEs ${ }^{1)}$ and T. ERICSSON ${ }^{2)}$
}

(Received $28^{\text {th }}$ October 2005)

\begin{abstract}
Wood density was analysed and annual ring width was measured on increment cores from 1400 trees in a 30-year-old full-sib progeny test of Scots pine (Pinus sylvestris L.) in north Sweden. Genetic parameters for wood density were analysed separately for ten outer annual rings, and for simple averages of the five most recent years. The evaluation included genetic correlations with height and stem diameter. Heritabilities of density estimated separately for each annual ring was 0.14-0.26 without any age trend, and jointly for the ten or five latest rings $0.30-0.33$; for height growth it was 0.30-0.42 and for stem diameter 0.11-0.13. Additive genetic correlations with height and stem diameter were negative with the simplest statistical model $\left(\hat{r}_{A}=-0.425\right.$ and 0.511 , respectively) but vanished or diminished when ring width was added as covariate. Density breeding values calculated for the parent trees for each of ten annual rings separately varied considerably between parent trees and between years, tending to increase with increasing age, with a substantial increase between the ages 14 to 16 years from the pith. This age fits well with literature data on the change from juvenile to mature wood. The genetic correlation for wood density between rings from different years was high: $\hat{r}_{A}=0.8$ ten years apart, increasing to 1.0 for neighbouring rings. The high genetic correlations for wood density between the innermost and outermost annual rings indicate possible strong covariation between juvenile and/or transition wood and mature wood. The annual variation in wood density in relation to genetic regulation, phenology, environmental conditions, and development from juvenile to mature age is discussed.
\end{abstract}

Key words: annual ring density, annual ring width, breeding value, genetic correlation, heritability, juvenile wood, mature wood, multitrait REML, repeated-measurement model, wood density.

\footnotetext{
$\left.{ }^{1}\right)$ Corresponding author: ANDERS FRIES, Department of Forest Genetics and Plant Physiology, Swedish University of Agricultural Sciences, SE-90183 Umeå, Sweden. Ph: +4690 78683 68, Fax: +4690786 8165. E-mail: anders.fries@genfys.slu.se.

2) Tore ERICsson, Skogforsk, Box 3, SE-918 21 Sävar, Sweden. Ph: +469020333 50, Fax: +46902033360. E-mail: tore.ericsson@skogforsk.se.
}

\section{Introduction}

There is an increasing pressure on the forest resources in Sweden and elsewhere. This includes both higher demand on economic profitability and a stronger opinion for saving forest land for nature conservation, recreation etc. To meet these conflicting demands, biomass, cellulose and wood production per unit area must be increased from the forests that are cut. A high wood density implies furthermore a higher production of wood biomass per unit volume. The economic pressures are also tending to favour shorter rotations, making the quality of the juvenile wood increasingly important (cf. KOUBAA et al., 2000). The quality of wood, juvenile or mature, can be improved in various ways, but appropriate breeding can clearly play a major role.

Thus, high biomass and cellulose yields from harvested wood are important breeding goals, and high wood density is a crucial trait for attaining them (e.g. ERICSON et al., 1973). Scots pine (Pinus sylvestris L.) breeding in Sweden has to date focused on survival, vitality, branching traits and volume growth, but little on wood density. However, in many studies phenotypic and genetic correlations between wood density and height have been found to be negative, as reviewed for spruce (Picea ssp.) in ROZENBERG and CAHALAN (1997) and reported for western hemlock (Tsuga heterophylla (Raf.) Sarg.) in KING et al. (1998). In Scots pine trees, HaNnRUP et al. (2000) reported genetic and phenotypic correlations between wood density and height close to zero, while wood density and ring width were negatively correlated for four different year intervals between the ages 2 and 33 years. There is a risk, therefore, that any increase in volume obtained may be counteracted by reductions in density. The need to assess this risk, and to explore the scope for avoiding it, prompted the combined analysis of wood density, height growth and ring width presented here.

Numerous pine studies have described positive correlations between wood density and strength properties of the wood, e.g. wood density and modulus of rupture (MOR) (ERICSON et al., 1973; WANG and WANG, 1999) and modulus of elasticity (MOE) in both juvenile and mature 
wood (WANG and WANG, 1999; LuO et al., 2002). KUMAR (2004) found strong genetic correlations in radiata pine between wood density and MOR and $\operatorname{MOE}\left(r_{A}=0.83\right.$ and 0.50 , respectively).

The relationships between wood density and strength properties of the pulp are, however, less clear, as reviewed in ROZENBERG and CAHALAN (1997): quality parameters such as sheet density, burst and tensile strength either decline with increasing wood density (ElliotT, 1970), or are not influenced by it. ERICSON et al. (1973) and DuPlooy (1980) have reported a negative influence of wood density on the strength of the pulp. The type and quality of produced pulp may be indirectly influenced by the proportion of earlywood and its density (CORSON, 1999; HANNRUP et al., 2004). Both wood density and fibre structure also influence the energy needed in the pulping process, and thus the costs and environmental effects associated with pulp production (CHAMBERS and BORRALHO, 1999).

Clearly, breeding for high biomass production, high yield and quality of the pulp, and breeding for strong wood products requires that genetic parameters for wood density and fibre traits in the breeding population are known before including the traits in the breeding programs. This is emphasized since wood is a heterogeneous material, and knowledge of the properties of the different wood types increases the scope for optimally using each type.

The present study focuses on the change in wood density by increasing age, and its correlation with growth traits. The change in genetic parameters (heritability, genetic variation and genetic correlation) is furthermore estimated. We study a sample from the Swedish breeding population of Scots pine in the age interval 20 to 29 years from seeding (ca. 12-21 years at breast height).

Within annual rings of mature wood the earlywood density is considerably lower than the latewood density since it has wider cells and thinner cell walls compared to the latewood (Evans et al., 1995). However, Evans et al. (1995) claim that the expansions of fibre cells occurs at different times and different time scales than cell wall formation. Thus, it is possible that single cells could have both large diameter and thick cell-walls, resulting in both high wood density and wide annual rings.

The material we examined should include the transition from juvenile to mature wood. However, the terms juvenile and mature wood are not clearly defined and open to discussion. One reason for this is that 'juvenile' wood is continuously produced in the upper part of the tree, starting in the first annual ring from the pith, and thus in both juvenile and mature trees. Another reason is that, as reviewed by COWN (1992) and BURDON et al. (2004), there is no approved definition for distinguishing between juvenile and mature wood, and biologically more correct terms are 'corewood' and 'outerwood' since both wood types are produced also in mature trees. Juvenile wood has considerably different characteristics which are undesirable for many purposes, and according to Cown (1992) and BURDON et al. (2004), a rapid increase in wood density is most often used for distinguishing the transition between the two wood types. We distinguish between 'juvenile' and 'mature' wood on the basis of this transition, and will attempt to identify the point at which low density 'juvenile wood' change to higher density 'mature wood'. This study concerns the whole ring wood density, i.e. without distinguishing earlywood and latewood. In articles following this, we plan to present results on wood density in earlywood and latewood separately.

The mature wood constitutes the major part of the stem in a full grown tree. However, as illustrated in Groom et al. (2002), the fraction of mature wood decreases towards the top of the tree. At a certain height, the transition zone between the juvenile wood and mature wood converges with the cambium and there is no mature wood. Thus, the fraction of juvenile wood increases along the stem towards the apex, even in a mature tree, and a full grown tall tree contains thus a considerable amount of juvenile wood in addition to the mature wood. The density of both these wood types must be considered in density analyses. Two factors that influence the percentage of juvenile wood are stem form and green crown limit (LARSON, 1962). However, our data set included no information on these variables.

\section{Material and Methods}

Wood samples were taken in a partial diallel progeny test planted in 1971 (S23F711261 Grundtjärn, at $63^{\circ} 33^{\prime} \mathrm{N}, 17^{\circ} 25^{\prime} \mathrm{E}$ on $320 \mathrm{~m}$ elevation) with 176 full-sib families sampled from the possible combinations of 40 phenotypically selected first generation parents originating from on average $63^{\circ} \mathrm{N}, 370 \mathrm{~m}$ elevation. The trees were regarded as a random sample from a population of plus trees crossed in accordance with a 'circulant' crossing scheme (KEMPTHORNE and CuRnOw, 1961; Table 1). Forty seedlings from each family were planted completely randomized at $2.2 \mathrm{~m}$ square spacing, giving about 7200 seedlings on 3.5 ha of typical forest land (moraine). The plantation has not been thinned since establishment. The trees were 30 years old in September 2001 , when about $45 \%$ of the planted trees had survived. Vitality, total tree height, and diameter at breast height were recorded, and wood samples were collected. The mean height was $17.7 \mathrm{~m}$ and mean diameter $13.8 \mathrm{~cm}$. Half of the experimental plantation was investigated. Thus, wood samples were extracted as increment cores from ca. 1600 trees in a selected geographic direction. A standard, manual increment borer was used to take cores with a diameter of approximately $5 \mathrm{~mm}$, extending from the bark towards the pith, resulting in the penetration of about 20 annual rings. Only undamaged or slightly damaged trees were bored. The two outermost annual rings were generally taken apart for fibre length analyses (results to be presented elsewhere). Thus, the annual rings from 1990 to 1999 were included in the density analysis.

Wood density was measured with an X-ray diffraction technique using an Itrax Density Scanner (Cox Analytical Systems, Gothenburg, http://www.coxsys.se / [January 5, 2006]). The device, which is described by LINDEBERG (2001) and BERGSTEN et al. (2001), enables the density of earlywood and latewood in each annual ring to be estimated separately after X-ray scanning. To obtain 
sufficient measurement precision the increment cores were sawn longitudinally, parallel with the wood fibres, into strips with widths ranging from $2.05-2.20 \mathrm{~mm}$. Furthermore, each sample width was measured manually with a precision of $0.01 \mathrm{~mm}$, and this exact measure was used as a correction factor in the X-ray analysis. The samples were subsequently conditioned for about 36 hours in the cabin of the density scanner, where the relative humidity always was typically $5-15 \%$. A Cu-diffraction X-ray tube with the beam perpendicular to the fibre direction and a power level of $1.925 \mathrm{~kW}$ at $35 \mathrm{kV}$ was used. The absorption was recorded, within a $1 \mathrm{~mm}$ wide longitudinal slot, stepwise at 5 steps per second and $0.025 \mathrm{~mm}$ between each step, giving a resolution of 1016 dpi. The total wavelength interval was $0.3-6.7 \AA$ with a maximum at $1.54 \AA$. Each exposure lasted $45 \mathrm{~ms}$. Nineteen increment cores and one reference plastic strip with a gradient of thickness, corresponding to known wood densities, were included in each run in the Itrax analyser. The $1 \mathrm{~mm}$ slots in the X-ray images were then analysed by Windendro software (Regent Instruments Inc. Canada) for density calculations. The X-ray absorptions were measured for earlywood and latewood separately. The borders between annual rings were set manually, based on the core strip image on a visual display unit. Absorptions were transferred to wood densities based on the reference strip measurements.

Each image was visually examined, and density measurements that were potentially unreliable due to wood irregularities, such as compression wood or highly slanting annual rings, were excluded and marked as missing since their inclusion could have increased the non-genetic variation in the data associated with irrelevant factors and thus impaired the genetic analysis. Since the frequency of such irregularities increases from the bark and inwards, the number of missing values increases correspondingly inwards (Table 2).

\section{Genetic models}

No significant variation caused by specific full-sib family effects (essentially genetic dominance) was detected in preliminary analyses, and despite the inevitable presence of such effects we assumed them to be of minor importance. Thus, the genetic model was based on the equation $P=A+E$, where $P$ is the phenotypic value, $A$ the additive genetic effect, and $E$ the independent environmental effect including the genetic residual. Their corresponding variances were assumed to be $\sigma_{P}^{2}=\sigma_{A}^{2}+\sigma_{E}^{2}$, assuming the sex of a parent being of less importance.

The statistical model used for individual tree-based multitrait analyses of the data set was constructed with a fixed-effects part and a random part. The fixed effects included block effects (the sampled area was subdivided into seven almost square, equal-sized blocks) with annual ring width as an optional covariate, since wood density comparisons between trees are often less reliable without adjustment for ring width (see, for examples, FRIES, 1986; ZAMUDIO et al., 2002).

The random part, which is connected to the genetic model, was constructed with genetic effects, tied to the parents of the full-sib families through a design matrix, and a relationship matrix, derived from the pedigree. This individual tree model separates the additive-genetic and remaining (residual $\approx$ environmental) effects. The covariances in the multiple trait analyses were, analogously, $\sigma_{P_{i j}}=\sigma_{A_{i j}}+\sigma_{E_{i j}}$ for traits $i$ and $j$. A variance like $\sigma^{2}{ }_{A}$ for a trait $i$ may be identified as $\sigma^{2}{ }_{A_{i}}=\sigma_{A_{i i}}$ in multiple-trait notation. Regarding heritabilities and genetic correlations, their estimates and standard errors were computed from the basic variance/covariance estimates as

$$
\frac{\hat{\sigma}_{A}^{2}}{\hat{\sigma}_{A}^{2}+\hat{\sigma}_{E}^{2}} \text { and } \frac{\hat{\sigma}_{A_{i j}}}{\sqrt{\hat{\sigma}_{A_{i i}}+\hat{\sigma}_{A_{j j}}}} \text {, }
$$

Table 1. - Number of trees per full-sib family (1655 trees in total). Parent trees are numbered in boldface (mothers vertically). Three crosses were represented with the reciprocals, by comparison with the original scheme.

\begin{tabular}{|c|c|c|c|c|c|c|c|c|c|c|c|c|c|c|c|c|c|c|c|c|c|c|c|c|c|c|}
\hline & 1 & 2 & 3 & 4 & 5 & 6 & 7 & 8 & 9 & 10 & 11 & 12 & 13 & 14 & 15 & 16 & 17 & 18 & 19 & 20 & 21 & 22 & 23 & 24 & 30 & 37 \\
\hline 12 & - & - & - & - & - & - & - & - & - & 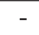 & - & - & 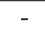 & & - & & - & - & 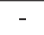 & - & - & - & - & - & 11 & - \\
\hline 17 & 11 & - & - & - & - & - & - & - & - & - & - & - & - & & - & & & - & & - & - & - & - & - & - & - \\
\hline 18 & 5 & 9 & - & - & - & - & - & - & - & - & - & - & - & - & - & - & - & - & - & - & - & - & - & - & - & - \\
\hline 19 & 11 & 10 & 15 & - & - & - & - & - & - & 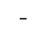 & - & - & . & & 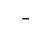 & & & 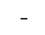 & & - & & 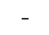 & - & & - & 10 \\
\hline 20 & 11 & 10 & 8 & 7 & - & - & - & - & - & 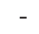 & - & . & & & 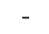 & & & & & - & & - & - & - & - & 12 \\
\hline 21 & 6 & 7 & 8 & 8 & 12 & - & - & - & - & - & - & - & - & & - & 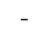 & - & - & & - & - & - & - & - & - & - \\
\hline 22 & 12 & 10 & 11 & 11 & 14 & $\varepsilon$ & - & - & - & - & - & - & - & - & - & - & & - & - & - & - & - & - & - & - & - \\
\hline 23 & 8 & 9 & 7 & 9 & 14 & 8 & 5 & - & - & - & - & - & - & - & - & 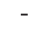 & - & - & - & - & - & - & - & - & - & - \\
\hline 24 & 14 & 8 & 9 & 6 & 8 & 8 & 8 & 9 & - & - & - & - & - & & - & & & & & - & - & - & - & - & - & - \\
\hline 25 & 9 & 6 & 11 & 8 & 8 & 7 & 12 & 12 & 12 & - & & 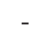 & _ & & - & & - & & & - & - & - & - & - & - & - \\
\hline 26 & - & 6 & - & 7 & 8 & 11 & 9 & 12 & 11 & 5 & - & 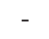 & 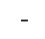 & & - & . & . & . & & - & 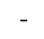 & - & - & - & - & - \\
\hline 27 & - & - & 15 & 10 & 11 & 7 & 6 & 10 & 13 & 3 & 8 & - & - & - & - & - & - & - & - & - & - & - & - & - & - & - \\
\hline 28 & - & - & - & 12 & 11 & 8 & 15 & 7 & 10 & 9 & 9 & 19 & - & 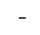 & - & - & - & - & - & - & - & - & - & - & - & - \\
\hline 29 & - & - & - & - & 10 & 4 & 1 & 8 & 7 & 12 & 6 & 15 & 4 & & - & 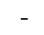 & - & - & - & - & - & - & - & - & - & - \\
\hline 3 & - & - & - & - & - & 7 & , & $\varepsilon$ & 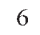 & 7 & 9 & & 10 & & 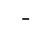 & 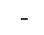 & - & - & - & - & - & - & - & - & - & - \\
\hline 31 & - & - & - & - & - & - & 9 & 8 & 7 & 5 & 8 & 15 & 8 & 15 & 11 & - & - & - & 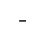 & - & - & - & - & - & - & - \\
\hline 3 & - & - & - & - & - & - & - & 8 & 12 & 9 & 11 & 6 & 6 & 8 & - & 1 & - & - & - & - & - & - & - & - & - & - \\
\hline 3. & - & - & - & - & - & - & - & - & - & - & 8 & 15 & 12 & 9 & 13 & 5 & 9 & - & - & - & - & - & - & - & - & - \\
\hline 3. & - & - & - & - & - & - & - & - & - & 9 & 13 & 9 & 7 & & 9 & 6 & 8 & & - & - & - & - & - & - & - & - \\
\hline 3 & - & - & - & - & - & - & - & - & - & - & 11 & 9 & 1 & 8 & 7 & 16 & 9 & 9 & 3 & - & - & - & - & - & - & - \\
\hline 36 & - & - & - & - & - & - & - & - & - & - & - & 8 & 11 & 4 & 12 & 8 & 13 & 8 & 11 & 9 & - & - & - & - & - & - \\
\hline 3 & - & - & - & - & - & - & - & - & - & - & - & - & 13 & 6 & 12 & 14 & 7 & 10 & - & - & 12 & - & - & - & - & - \\
\hline 3 & - & - & - & - & - & - & - & - & - & - & - & - & - & 16 & 10 & 16 & 13 & 8 & 12 & 12 & 8 & 10 & - & - & - & - \\
\hline 3 & - & - & - & - & - & - & - & - & - & - & - & - & - & - & 6 & 12 & 11 & 15 & 9 & 8 & & 7 & 10 & - & - & - \\
\hline 40 & - & - & - & - & - & - & - & - & - & - & - & - & - & - & - & 6 & 8 & 12 & 14 & $J$ & 7 & 5 & 7 & 5 & - & \\
\hline
\end{tabular}


respectively (other correlations in analogy), with approximate standard errors obtained from the basic error variance estimates and first order Taylor expansion.

\section{Between-year density variation}

To get a view of the variation within the samples from each year we made a preliminary calculus on the ten analysed annual rings separately. The field test sampled in this investigation was planted in spring 1971, and a parallel field test in the same test series was measured and thoroughly evaluated in another study (ERICSSON and FRIES, 2004). By comparison with the annual rings from that evaluation, we estimated that the annual rings studied here, from 1990 to 1999 , should cover the breast height age interval 12-21 years, i.e. from 12 to 21 years on average from the pith. In order to elucidate the density variation between the ten outermost rings in sequence, a ten-trait genetic analysis was designed, based on the density equation $\mathbf{y}=\mathbf{X b}+\mathbf{Z u}+\mathbf{e}$, where $\mathbf{X}$ is the fixed-effect design matrix including block effects along with ring-width, which was entered as the covariate $\mathbf{w}$ in $\mathbf{X}=\left[\mathbf{X}_{\text {blocks }} \mathbf{w}\right] . \mathbf{Z}$ is the design matrix for the additive random effects associated with the parents. Assuming $\mathbf{y}=\left[\begin{array}{llll}\mathbf{y}_{1}^{\prime} & \mathbf{y}_{2}^{\prime} & \ldots & \mathbf{y}_{10}^{\prime}\end{array}\right]^{\prime}$ is the vector that combines the density values from each of ten rings from each of the trees, along with corresponding structures in the right-hand equation terms, the basic covariances (including variances) to be estimated are

$$
\operatorname{Var}\left[\begin{array}{l}
\mathbf{u} \\
\mathbf{e}
\end{array}\right]=\left[\begin{array}{cc}
\mathbf{G} \otimes \mathbf{A} & \mathbf{0} \\
\mathbf{0} & \mathbf{R} \otimes \mathbf{I}_{n}
\end{array}\right]
$$

through the symmetric additive genetic and residual covariance matrixes $\mathbf{G}$ and $\mathbf{R}$, respectively: $\mathbf{G}=\left\{\sigma_{A_{i j}}\right\}_{10 \times 10}$ and $\mathbf{R}=\left\{\sigma_{E_{i j}}\right\}_{10 \times 10}$, both symmetric. The diagonal elements $\sigma_{A_{i i}}$ and $\sigma_{E_{i i}}$ will estimate the variances for density of ring number $i$. A is the additive relationship $n \times n$ matrix for the $n$ trees analysed. Assuming $\mathbf{R}_{\mathbf{I}}=\mathbf{R}^{-1} \otimes \mathbf{I}_{n}$, the corresponding HENDERSON (1986) mixed-model equations are

$$
\left[\begin{array}{cc}
\mathbf{X}^{\prime} \mathbf{R}_{\mathbf{I}} \mathbf{X} & \mathbf{X}^{\prime} \mathbf{R}_{\mathbf{I}} \mathbf{Z} \\
\mathbf{Z}^{\prime} \mathbf{R}_{\mathbf{I}} \mathbf{X} & \mathbf{Z}^{\prime} \mathbf{R}_{\mathbf{I}} \mathbf{Z}+\mathbf{G}^{-1} \otimes \mathbf{A}^{-1}
\end{array}\right]\left[\begin{array}{l}
\mathbf{b} \\
\mathbf{u}
\end{array}\right]=\left[\begin{array}{c}
\mathbf{X}^{\prime} \mathbf{R}_{\mathbf{I}} \mathbf{y} \\
\mathbf{Z}^{\prime} \mathbf{R}_{\mathbf{I}} \mathbf{y}
\end{array}\right],
$$

used for the REML estimation of $\mathbf{G}$ and $\mathbf{R}$ and corresponding approximate BLUP breeding values $\mathbf{u}$. The analyses were carried out with the computer software ASReml (GILMOUR et al., 2002), which essentially iterates an AI algorithm (GILMOUR et al., 1995) until convergence, starting from given rough estimates of $\mathbf{G}$ and $\mathbf{R}$ or corresponding correlation matrices and variances. The data did not permit all $(2 \cdot 10 \cdot 11) / 2=110$ covariances to be estimated, and all densities within a tree sample were highly correlated. Thus, a banded correlation structure was imposed on $\mathbf{G}$, while $\mathbf{R}$ could be estimated without restrictions (in total $55+19=74$ parameters to estimate). Despite these precautions, the resulting G matrix was slightly inconsistent, although nearly positive definite, thus further approximate besides approximations by the model and the imposed restrictions.

\section{Tree density values}

A trivariate (wood density, tree height, and tree diameter at breast height) genetic analysis was then undertaken, adding annual ring width as a possible covariate. The equation setup was similar to that described above, except that only three traits were considered instead of ten. We intended to design a method of analysis for the primary purpose to discriminate between trees in a straightforward and unambiguous manner, taking into account that the density records are carrying much of environmental influence and even measurement errors.

The utility of several possible model equation set-ups was evaluated in this analysis. We present results obtained from three of the most useful of these models in Table 3, the first being a simple analysis of five-year density means. The second is like the first, except that mean annual ring width was used as an adjusting covariate to the fit genetic model to the density data.

Table 2. - Estimates from the approximate multiple-trait analysis of wood density in ten annual rings: Heritabilities $\left(h^{2}\right)$ along the bold-face diagonal, additive genetic correlations $\left(r_{A}\right)$ above the diagonal, environmental correlations $\left(r_{E}\right)$ below the diagonal, phenotypic variances $\left(\sigma_{P}^{2}\right)$, mean densities $\left(\mathrm{kg} \cdot \mathrm{m}^{-3}\right)$, genetic coefficients of variation $\left(\mathrm{CV}_{A}\right)$, and the number of analysed samples (trees) per annual ring $\left(n_{\mathrm{yr}}\right)$.

\begin{tabular}{llllllllllllll}
\hline $\begin{array}{c}\text { Annual } \\
\text { ring }\end{array}$ & $1990^{\mathrm{a}}$ & 1991 & 1992 & 1993 & 1994 & 1995 & 1996 & 1997 & 1998 & 1999 & $\sigma_{P}^{2}$ & $\begin{array}{c}\text { Mean } \\
\text { density }\end{array}$ & $\mathrm{CV}_{A}$ \\
\hline 1990 & $\mathbf{0 . 1 4}$ & 1.00 & 0.96 & 0.95 & 0.93 & 0.89 & 0.86 & 0.81 & 0.76 & 0.81 & 2438 & 423.7 & $4.3 \%$ \\
1991 & 0.61 & $\mathbf{0 . 1 7}$ & 1.00 & 0.96 & 0.95 & 0.93 & 0.89 & 0.86 & 0.81 & 0.76 & 1872 & 416.3 & $4.3 \%$ \\
1992 & 0.49 & 0.70 & $\mathbf{0 . 2 6}$ & 1.00 & 0.96 & 0.95 & 0.93 & 0.89 & 0.86 & 0.81 & 1855 & 420.9 & $5.2 \%$ \\
1993 & 0.45 & 0.50 & 0.63 & $\mathbf{0 . 1 5}$ & 1.00 & 0.96 & 0.95 & 0.93 & 0.89 & 0.86 & 2288 & 444.1 & $4.2 \%$ \\
1994 & 0.47 & 0.54 & 0.51 & 0.65 & $\mathbf{0 . 2 0}$ & 1.00 & 0.96 & 0.95 & 0.93 & 0.89 & 2822 & 469.7 & $5.0 \%$ \\
1995 & 0.38 & 0.56 & 0.55 & 0.43 & 0.52 & $\mathbf{0 . 1 9}$ & 1.00 & 0.96 & 0.95 & 0.93 & 2525 & 466.7 & $4.7 \%$ \\
1996 & 0.42 & 0.53 & 0.59 & 0.56 & 0.60 & 0.55 & $\mathbf{0 . 2 0}$ & 1.00 & 0.96 & 0.95 & 2354 & 471.8 & $4.7 \%$ \\
1997 & 0.47 & 0.57 & 0.57 & 0.54 & 0.64 & 0.58 & 0.71 & $\mathbf{0 . 1 6}$ & 1.00 & 0.96 & 2360 & 476.5 & $4.1 \%$ \\
1998 & 0.36 & 0.54 & 0.54 & 0.36 & 0.39 & 0.64 & 0.54 & 0.59 & $\mathbf{0 . 2 2}$ & 1.00 & 2711 & 453.4 & $5.4 \%$ \\
1999 & 0.30 & 0.39 & 0.45 & 0.39 & 0.39 & 0.30 & 0.50 & 0.55 & 0.42 & $\mathbf{0 . 1 5}$ & 3259 & 461.2 & $4.9 \%$ \\
\hline$n_{\mathrm{yr}}{ }^{\mathrm{c}}$ & 891 & 973 & 859 & 879 & 1006 & 1142 & 1149 & 1202 & 1216 & 1124 & & &
\end{tabular}

\footnotetext{
a Approx. 12 years from the pith

b Total mean $=450.5 \mathrm{~kg} \cdot \mathrm{m}^{-3}$

c Data from 1427 trees in total.
} 
In the third, a repeated-measurement approach was employed, in which each year's density record was considered a new measurement of the same tree. This allows maximum utilization of the available data, since even incomplete series of ten-year density records may be fully utilized through the proper handling of missing data that is implemented in the software used. A number of approaches were tested, and a covariance set-up was finally selected in which the annual ring width was taken as a fixed-effect covariate on a within-year and within-block basis (70 'adjusting regressions'). The adjustment for both year, block, and ring width effects should allow as much of the genetic influence on wood density as the data allows to be revealed.

\section{Results}

Between-year variation in wood density and it's heritability

The results elucidate variation between years in wood density and its heritability (Table 2), and corresponding breeding values of the 40 contributing parent trees (Fig. 1 ). The major change in wood density was the rise from $420.9 \mathrm{~kg} / \mathrm{m}^{3}$ to $469.7 \mathrm{~kg} / \mathrm{m}^{3}$ in the wood formed in 1992 and 1994, respectively (Table 2). There was also a peak in 1997 , but only a moderate decrease to 1998 , and then a slight increase. The highest heritability occurred in 1992, and the second highest as late as 1998, while the lowest occurred in 1990, and the joint second lowest in the last year, 1999, and 1993. The genetic coefficients of variation $\left(\mathrm{CV}_{A}\right)$ followed the same pattern. There was no correlation between average wood density and heritability $(r=-0.067, p>0.05)$.

There was a rise in wood density from 1991 to 1994, especially $1992-1994$, i.e. $13-16$ years from the pith
(Table 2), which may indicate the decline of juvenile wood formation and onset of mature wood formation. Starting from the year 1994, there was also an improved discrimination among parent trees in wood density and their breeding values (Fig. 1a).

\section{Tree density values and correlations with growth traits}

The first model with three traits (mean density, tree height and diameter at breast height) and no covariate resulted in significant negative genetic correlations between density and both height and diameter $\left(\hat{r}_{A}=\right.$ -0.42 and -0.51 , respectively; Table 3 ), while the two growth traits were positively correlated.

Including mean ring width as a covariate removed all detectable genetic correlations between density and the growth traits (see the second section of Table 3). Including ring width as a covariate also reduced the estimate of environmental correlation between density and diameter from -0.24 to -0.16 , while the environmental correlation between height and density was non-detectable both with and without this covariate.

The last section of Table 3 shows results obtained when using the repeated-measurement model. Analysing ten annual rings per tree, with each ring width as a covariate, changed the pattern slightly. According to this model, diameter was significantly genetically correlated with wood density $(-0.42)$, and with tree height the environmental correlation was estimated to be slightly positive $(0.16$; Table 3$)$.

\section{Breeding values and heritabilities}

The heritabilities based on the five latest years (1995-1999) for wood density and height were at least 0.3 in the models both with and without covariate, but lower for diameter (around 0.1; Table 3). The breeding

Table 3. - Results (estimates with standard errors) from genetic analysis of mean wood density of the annual rings from 1995-1999 without and with a covariate, and of the rings from 1990-1999 as repeated measures with a covariate: ring width was used as a fixedeffect for adjusting mean density in the covariance analysis. Estimated heritabilities $\left(h^{2}\right)$ along the bold-face diagonal, additive genetic correlations $\left(r_{A}\right)$ above the diagonal, and environmental correlations $\left(r_{E}\right)$ below. $\sigma_{P}^{2}=$ phenotypic variance, $\mathrm{CV}_{A}=$ additive coefficient of variation. Mean density from 909 trees with five complete records; data from 1427 trees in total.

\begin{tabular}{lcccccc}
\hline Trait & Density & Height & Diameter & $\sigma_{P}^{2}$ & $\mathrm{CV}_{A}$ & Mean \\
\hline \multicolumn{7}{c}{ No covariate (mean density of 5 annual rings): } \\
Density & $\mathbf{0 . 3 3 3} \pm \mathbf{0 . 0 7 5}$ & $-0.425 \pm 0.116$ & $-0.511 \pm 0.160$ & $2183.0 \pm 129.5$ & $5.8 \%$ & $466.7 \mathrm{~kg} \cdot \mathrm{m}^{-3}$ \\
Height & 0 & $\mathbf{0 . 3 0 4} \pm \mathbf{0 . 0 6 6}$ & $0.477 \pm 0.154$ & $137.2 \pm 6.9$ & $5.8 \%$ & $111.6 \mathrm{dm}$ \\
Diameter & $-0.238 \pm 0.038$ & $0.691 \pm 0.026$ & $\mathbf{0 . 1 2 0} \pm \mathbf{0 . 0 3 8}$ & $1072.5 \pm 43.2$ & $7.4 \%$ & $154.2 \mathrm{~mm}$ \\
& Ring width ${ }^{\mathrm{a}}$ as covariate for density (means of 5 annual rings): & & \\
Density & $\mathbf{0 . 3 0 7} \pm \mathbf{0 . 0 7 7}$ & 0 & 0 & $1923.8 \pm 113.7$ & $5.2 \%$ \\
Height & 0 & $\mathbf{0 . 2 9 2} \pm \mathbf{0 . 0 6 9}$ & $0.449 \pm 0.169$ & $136.4 \pm 6.9$ & $5.7 \%$ \\
Diameter & $-0.160 \pm 0.030$ & $0.694 \pm 0.025$ & $\mathbf{0 . 1 1 3} \pm \mathbf{0 . 0 3 7}$ & $1072.3 \pm 42.6$ & $7.1 \%$ & \\
& Ring width as within-year-and-block ${ }^{\mathrm{b}}$ covariate for density, 10 annual rings: & & \\
Density & $\mathbf{0 . 2 9 6} \pm \mathbf{0 . 0 7 0}$ & 0 & $-0.416 \pm 0.151$ & $1492.1 \pm 82.0$ & $4.5 \%$ & \\
Height & $0.165 \pm 0.040$ & $\mathbf{0 . 4 1 6} \pm \mathbf{0 . 0 9 2}$ & $0.383 \pm 0.174$ & $97.1 \pm 7.0$ & $5.7 \%$ & \\
Diameter & 0 & $0.984 \pm 0.045$ & $\mathbf{0 . 1 2 6} \pm \mathbf{0 . 0 3 9}$ & $942.8 \pm 42.1$ & $7.1 \%$ & \\
\hline
\end{tabular}

a Mean $=1.815 \mathrm{~mm}$, slope $=-21.23 \mathrm{~kg} \cdot \mathrm{m}^{-3} \cdot \mathrm{mm}^{-1}$

$\mathrm{b}$ Ten-year repeated-measurement model (each annual ring considered separately) Within-tree residual wood density variance $=1077.0$ 

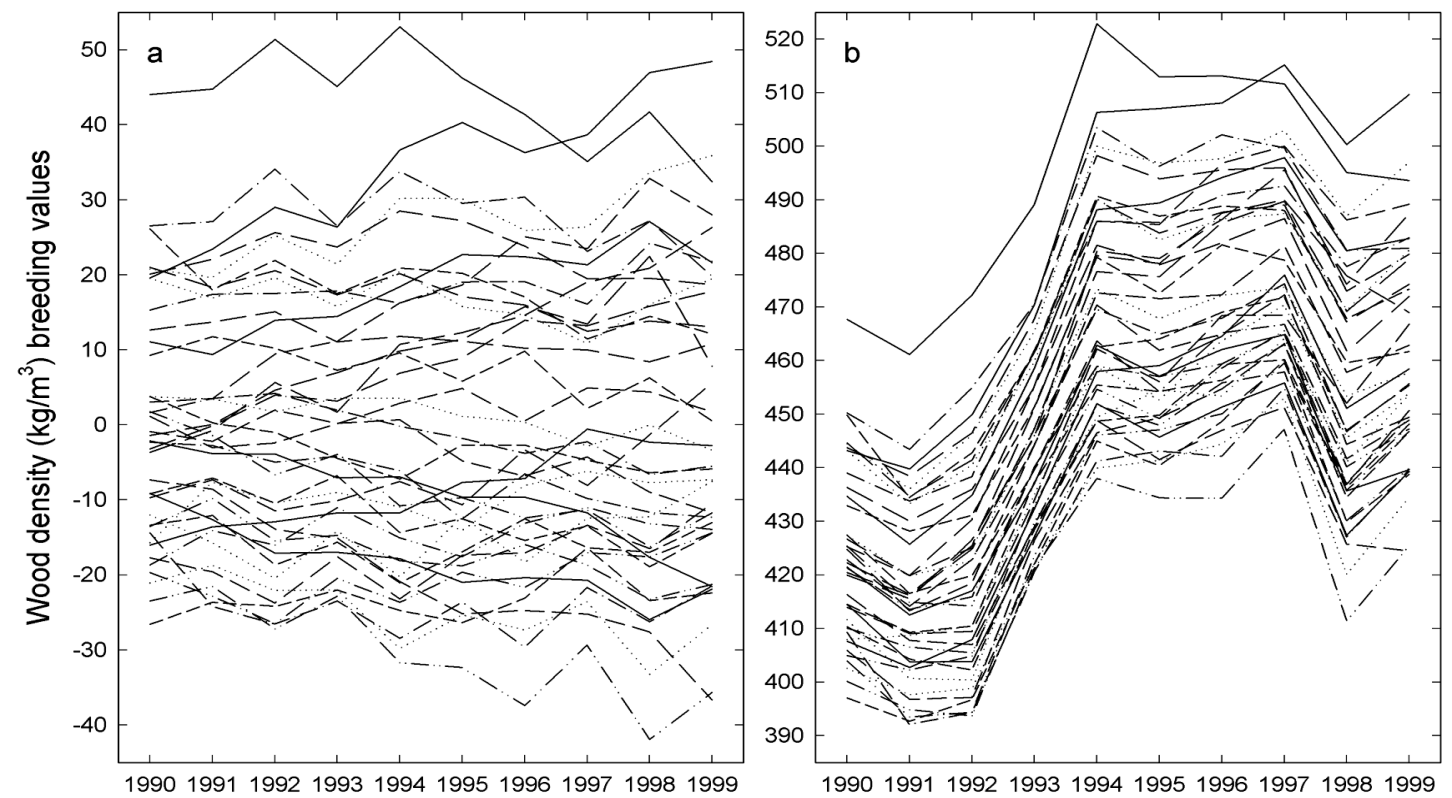

Figure 1. - Annual ring wood density. Breeding values of the 40 parents of the assessed trees from the approximate multiple-trait analysis, where density records from each ring were treated as separate traits.

a Deviation of breeding values from the mean; b Total breeding values, including the mean.

values derived from the evaluations with and without covariate were, in addition, highly correlated ( $r=0.98$ ), except that the adjustment through covariation shrinked them roughly $10-30 \%$ against zero with a correspondingly lower standard error. Heritabilities for each separate year were lower, varying from 0.14 to 0.26 (Table 2).

Over the course of the 10-year period, the breeding values of the 40 parents diverged (Fig. 1a), but this is merely a result of higher breeding values (Fig. $1 b$ ). Wood density breeding values of parents with above-average values tended to increase, while those of parents with below average values tended to decrease. However, the trends for some parents deviated from these general patterns (without being worse than generally represented as regards missing crosses and mortality; cf. Table 1).

\section{Discussion}

The data records did not permit a fully parameterized genetic model to be constructed for the between-year analysis since the densities in adjacent rings were, as expected, highly correlated (Table 2). However, the banded-correlation restriction with preset near-unit genetic correlations between neighbouring rings did result in an approximate estimate of the pattern in additive genetic variation with a slightly ill-conditioned (not fully positive definite) additive genetic correlation matrix (Table 2). Although we failed to carry the tenring analysis to an unambiguous end, the results should provide some information about the nature of wood density patterns.

\section{Wood density development over years}

Beside the general increase in breeding values, there was a year-to-year variation (Table 2 , Fig. 1b), which may be caused by annual differences in growth (weather) conditions resulting in varying annual ring struc- tures. Different distributions of earlywood vs. latewood amount should be an important factor that has to be studied further.

For defining the border between the juvenile and mature wood, a rapid increase in total ring density is most frequently used, and also recommended by Cown (1992). The field test in the present study was planted in spring 1971, and the same full-sib families were used in a parallel field test located at a more northerly site, but lower altitude $\left(64^{\circ} \mathrm{N}, 200 \mathrm{~m}\right.$ a.s.l.) (ERICSSON and FRIES, 2004). In that test, the trees reached $80 \mathrm{~cm}$ height at an average age of 6 years, which should correspond to ca 8 years at breast height in the test studied here. Thus, we estimate that the years in which the annual rings studied here were formed (at breast height where the samples were taken), 1990-1999, should cover the age interval 12-21 years from pith at breast height (cf. Table 2).

Loo et al. (1985) and SAUTER et al. (1999) identified a similar increase as in the present study at approximate ages 10-12 years from pith. HANNRUP et al. (2000) stated an increase up to age 26 , but it was more gradual. Thus, the dramatic increase we found from 1992 to 1994 (Table 2, Fig. 1b), corresponding to 14-16 years from the pith, coincides quite well with the age intervals (10-20 years of age) obtained for Scots pine by SAUTER et al. (1999) and Hannrup et al. (2000), and for loblolly pine (Pinus taeda L.) by Loo et al. (1985). It is therefore possible that this age interval covers the transition zone, and the increase we detected between 1992 and 1994 may indicate the decline of juvenile wood formation and onset of mature wood formation. However, the increase could also be due, at least in part, to annual variations, as indicated by the differences between the other years.

A difficulty associated with wood density analyses is that the trait is considerably influenced by weather conditions and environmental factors, both directly and 
indirectly via their effects on the growth rate. Thus, when studying genetic parameters associated with wood density, efforts should be taken to establish homogeneous field tests and to use replicates both in time and space. If the age interval studied here covers the transition from juvenile to mature wood formation, the high genetic correlations in ring density for the longest time intervals, eight years $\left(r_{A}=0.81\right)$ and nine years $\left(r_{A}=\right.$ 0.76 ), indicate that the density of juvenile and mature wood were positively correlated (Table 2). These high genetic correlations, and additional high correlations between any distant years $\left(r_{A} \approx 0.8\right)$, suggest that it should be possible to use breeding values estimated for wood formed at young ages for wood formed at higher ages, and that there is a strong correlation between breeding values for juvenile wood and mature wood, or at least moderately mature wood. Similar genetic correlations between the densities of recently formed and older wood were obtained by HANNRUP and EKBERG (1998) for wood aged 8-11 and 28-33 years $\left(r_{A}=0.88\right)$ and by LOO and TAUER (1984), who found that density for each of the years $4,6,8$, and 10 from the pith were strongly correlated with density at 25 years from the pith $\left(r_{A}=0.9-1.0\right)$. In addition, WANG et al. (2000) found stronger correlations in lodgepole pine for family ranking between the ages 4 and 12 years for earlywood density separately than for whole ring density. Between annual ring 4 and 25, the correlation was however, relatively low $\left(r_{A}=0.3\right)$, but high already between ages 12 and 25 years $\left(r_{A}=0.9\right)$.

Thus, the results of this and other studies provide quite strong evidence that wood density at juvenile age (less than ca. 14 years) is genetically correlated with density in the transition zone or at young mature age (ca. 20 years). However, analyses spanning longer periods are needed to elucidate the correlations between juvenile and true mature wood density more thoroughly.

The expected high genetic correlations between adjacent years were not accompanied by such high environmental correlations (values below the diagonal in Table 2 ), indicating that non-genetic factors caused betweenyear variations in wood density. One such factor is variation in the length of the growing season, which leads to variation in the proportions of low-density earlywood and high-density latewood. For this reason, the duration of the cambial growth period and the time when latewood formation is initiated in a given year, i.e. the phenology, strongly influences the total density of the corresponding annual ring (cf. VARGAS-HERNANDEZ and ADAMS, 1994). Phenological traits are strongly inherited (YAZDANI et al., 2003), but between-year variations in the prevailing weather conditions modify the timing of sprouting and growth cessation. In years when the temperature decreases rapidly in the autumn, and thus growth ceases relatively rapidly, the proportion of latewood should be smaller for all families and less dependent on their inherited phenology. Due to the larger relative amount of low-density earlywood formed when growth ceases rapidly, the overall density should also be lower. Thus, variations in overall ring density could be indirectly related to genetic differences in phenology.

\section{Heritability}

The heritability for wood density is very similar to that found by FrIES (1986) in 9-year-old lodgepole pine (Pinus contorta Douglas ex Loudon), while HANNRUP et al. (2000) for Scots pine reported about 35\% higher heritability, and KING et al. (1998) reported twice as high heritabilities in 13-year-old western hemlock. For jack pine (Pinus banksiana Lamb.), ZHANG and CHUI (1996) found that the heritability for density was $50 \%$ higher, and for height more than twice as large as in the present study. Many studies of radiata pine have also reported considerably higher estimates (see KIBBLEwhite, 1999; Kumar, 2004; NyankuEnGAMA et al., 1997; ShElbourne et al., 1997, for instance). However, this was most probably because the sites examined in the cited studies were more homogeneous than the sites in our study, giving lower environmental variance. NYANKUENGAMA et al. (1997) found moderate genetic control of wood density in radiata pine up to ages $4-5$ years $\left(h^{2} \approx 0.1\right.$ ), a drop during the transition zone, and a gradual increase to heritabilities greater than 0.7 after 16 years. ZAMUDIO et al. (2002) showed a somewhat different pattern: strong genetic control of density at low age, lower at transition age (ca. six years from the pith), and then moderate heritability, but as in our material, characterized by large fluctuations up to age 14 years. Large fluctuations in heritability for total ring density may be due to the large environmental influence, mainly annual differences, in temperature sum.

The general pattern for the ten studied years was lack of correlation between wood density and its heritability and with fluctuating heritabilities (here between 0.14 and 0.26). Based on LOUZADA and FonseCA (2002) some correlation should be expected if the earlywood-latewood proportions vary and the heritability is higher for one of them. However, according to LARSON (1962), the earlywood-latewood ratio is also influenced by crown size, and thus indirectly by stand density and crown closure. Thus, the unevenness of the stands we sampled, due to the relatively high mortality (45\%) may have influence on the results.

\section{Multitrait analysis and correlations with growth traits}

Several ways of modelling genetic effects on woodproperty traits were tested in multitrait analyses, and the results of three models are shown in Table 3. Depending on whether a certain recorded variable is considered a trait or an environmental descriptor, analyses may give quite different results. Our first case assumes three traits and blocking as the only fixed effect. The density data used were the mean densities of five annual rings, to detect differences among trees. The correlations with diameter are quite strong and negative, in accordance with the established finding that wide rings tend to have lower density than narrow rings.

Since density measurements are usually adjusted for annual ring width, the next model shown includes the mean ring width as a covariate, i.e. a fixed-effect for which adjustments are made like any environmental factor. This may improve the precision of the genetic analysis by reducing the phenotypic variance. On the 
other hand, since ring width and diameter are closely related, all genetic correlation between density and diameter is removed. One may argue that this is an unrealistic model that merely 'removes' a biological connection by mathematical manipulation.

The third approach may be more realistic, since it adjusts for annual ring width only within each year and block combination (a two-way environmental blocking). Thus, the mean ring width of individual trees has no direct influence, but the comparison between trees is still made with adjustment for ring widths. The effective tree density record is a mean of adjusted densities from all annual rings measured on that tree. The choices of using either 'year' or 'block' as a single blocking factor for ring-width covariation did make less sense, since they both produced ill-conditioned solutions (non-positive definite covariance matrix estimates).

The third approach has still another advantage: all available data are utilized. The first two cases require complete density records for five annual rings in order to obtain a mean value, while the analysis based on individual annual rings compensates for occasionally missing density records automatically. Although the phenotypic variation estimated using this approach (1492.1) is lower for the most part, the genetic correlation with diameter still remains at roughly the same level as in the first analysis, but there is no detectable genetic correlation with height. The third analysis further suggests that height growth has a slight positive environmental correlation with wood density, and that there is no such correlation with diameter.

Apart from heritability and $\mathrm{CV}_{A}$ estimates remaining roughly the same, we suggest that the third way of taking ring width into account is the best of these alternatives. Ring width is considered an environmental variable for density comparisons between trees without being strongly confounded with the tree size traits. The strong genetic correlation between density and diameter is preserved using this approach, while a seeming genetic connection between density and tree height is defused (cf. HANNRUP et al., 2000, using a different model).

\section{Conclusions}

The total ring density of ten outer annual rings in 30 year old Scots pine had a heritability of ca 0.3 , which was similar to that for tree height, and higher than for stem diameter. The genetic correlation between wood densities in the transition zone from juvenile to mature wood was high indicating that even young trees can be assessed and compared for future wood density.

The different models we show for genetic evaluation do emphasize that the construction of an informative statistical model for a wood property trait may be laborious, even under minimal genetic assumptions. We used annual ring width as a covariate in the traditional way within an overall attempt to distinguish wood density as independently as possible from environmental influences: climatic factors, scaling circumstances, auto-covariation for tree size, and so on. We propose a model that we found most fruitful showing no genetic correlation with tree height, but negative with diameter. On the other hand, with another model, wood density showed genetic correlation with neither height nor diameter. We intend to analyse earlywood and latewood separately in further analyses.

\section{Acknowledgements}

The project received important economic support by Föreningen Skogsträdsförädling, Uppsala, Sweden. Kempestiftelserna, Örnsköldsvik, Sweden provided economic resources for the laboratory equipment and instruments used for sample preparation and wood density analyses. JOHAN LINDEBERG, Department of Silviculture, SLU, Umeå, Sweden, gave valuable advice during the wood analyses. We also acknowledge two anonymous reviewers who presented fruitful ideas and suggested substantial improvements of the manuscript.

\section{References}

Bergsten, U., J. Lindeberg, A. Rindby and R. Evans (2001): Batch measurements of wood density on intact or prepared drill cores using x-ray microdensiometry. Wood Sci. Tech. 35: 435-452.

Burdon, R. D., R. P. KibBlewhite, J. C. F. WAlker, R. A. Megraw, R. Evans and D. J. Cown (2004): Juvenile versus mature wood: a new concept, orthogonal to corewood versus outerwood, with special reference to Pinus radiata and P. taeda. For. Science 50: 399-415.

Chambers, P. G. S. and N. M. G. Borralho (1999): A simple model to examine the impact of changes in wood traits on the costs of thermomechanical pulping and high-brightness newsprint production with radiata pine. Can. J. For. Res. 29: 1615-1626.

Corson, S. R. (1999): Tree and fibre selection for optimal TMP quality. Appita 52: 351-357.

Cown, D. J. (1992): Corewood (juvenile wood) in Pinus radiata - should we be concerned? New Zeal. J. For. Sci. 22: 87-95.

Elliott, G. K. (1970): Wood density in conifers. Tech. Commun. For. Bur. 8. Farnham Royal, Oxford, 44 pp..

Ericson, B., T. Johnson and A. Persson (1973): Wood and sulphate pulp of Scots pine from virgin stands. Swedish Royal College of Forestry, Dept For. Yield Res. Notes 25, $143 \mathrm{pp}$.

ERICSSON, T. and A. Fries (2004): Genetic analysis of fibre size in a full-sib Pinus sylvestris L. progeny test. Scand. J. For. Res. 19: 7-13.

Evans, R., G. Downes, D. Menz and S. Stringer (1995): Rapid measurement of variation in tracheid transverse dimensions in a radiata pine study. Appita 48: 134-138.

FRIES, A. (1986): Volume growth and wood density of plus tree progenies of Pinus contorta in two Swedish field trials. Scand. J. For. Res. 1: 403-419.

Gilmour, A. R., R. Thompson and B. R. Cullis (1995): Average information REML: An efficient algorithm for variance parameter estimation in linear mixed models. Biometrics 51: 1440-1450.

Gilmour, A. R., B. J. Gogel, B. R. Cullis, S. J. Welham and R. Thompson (2002): ASReml User Guide. Hemel Hempstead: VSN International, $267 \mathrm{pp}$.

Groom, L., S. Shaler and L. MotT (2002): Mechanical properties of individual southern pine fibers. Part III: Global relationships between fiber properties and fiber location within an individual tree. Wood and Fiber Sci. 34: 238-250.

HANNRUP, B. and I. EkBERG (1998): Age-age correlations for tracheid length and wood density in Pinus sylvestris. Can. J. For. Res. 28: 1373-1379. 
Hannrup, B., I. EkBerg and A. Persson (2000): Genetic correlations between wood, growth capacity and stem traits in Pinus sylvestris. Scand. J. For. Res. 15: 161-170.

Hannrup, B., C. Cahalan, G. Chantre and M. Grabner et $a l$. (2004): Genetic parameters of growth and wood quality traits in Picea abies. Scand. J. For. Res. 19: 14-29.

Henderson, C. R. (1986): Recent developments in variance and covariance estimation. J. Anim. Sci. 63: 208-216.

KEMPTHORNE, O. and R. N. CURNOW (1961): The partial diallel cross. Biometrics 24: 229-250.

KIBBLEWHITE, R. P. (1999): Designer fibres for improved papers through exploiting genetic variation in wood microstructure. Appita 52: 429-435 and 440.

King, J. N., C. Cartwright, J. Hatton and A. D. Yanchuk (1998): The potential of improving western hemlock pulp and paper quality. I. Genetic control and interrelationships of wood and fibre traits. Can. J. For. Res. 28: 863-870.

KoubaA, A., S. Y. Zhang, N. Isabel, J. Beaulieu and J. Bousquet (2000): Phenotypic correlations between juvenile-mature wood density and growth in black spruce. Wood and Fiber Sci. 32: 61-71.

KUMAR, S. (2004): Genetic parameter estimates for wood stiffness, strength, internal checking, and resin bleeding for radiata pine. Can. J. For. Res. 34: 2601-2610.

LARSON, P. H. (1962): A biological approach to wood quality. Tappi 45: 443-448.

LINDEBERG, J. (2001): X-ray based dendro-analyses of wood properties. Lic. Thesis, Dept. of Silviculture, Swedish Univ. Agric. Sci., Report 50: 18 pp.

Loo, J. A. and C. G. TAUER (1984): Juvenile-mature relationships and heritability estimates of several traits in loblolly pine (Pinus taeda L.). Can. J. For. Res. 14: 822-825.

Loo, J. A., C. G. TAuer and R. W. McNew (1985): Genetic variation in the time of transition from juvenile to mature wood in loblolly pine (Pinus taeda L.). Silvae Genet. 34: 14-19.

LouzadA, J. L. P. C. and F. M. A. FonsecA (2002): The heritability of wood density components in Pinus pinaster Ait. and the implications for tree breeding. Ann. For. Sci. 59: 867-873.
LuO, X.-Q., X.-M. JIANG, Y.-F. YIN, Y.-Q. LI and B.-G. WANG (2002): Variations in wood properties of Masson pine (Pinus massoniana Lamb.) plantation. For. Res. Beijing 15: 28-33.

Nyankuengama, J. G., C. Matheson, D. J. Spencer, R. Evans and P. VINDEN (1997): Time trends in the genetic control of wood microstructure traits in Pinus radiata. Appita 50: 486-494.

DuPlooy, A. B. J. (1980): The relationship between wood and pulp properties of $E$. grandis (Hill ex-Maiden) grown in South Africa. Appita 33: 257-264.

RozenberG, P. and C. CAHALAN (1997): Spruce and wood quality: genetic aspects (a review). Silvae Genet. 46: $270-279$.

SAuter, U. H., R. RÜDiger and B. D. MunRo (1999): Determining juvenile-mature wood transition in Scots pine using latewood density. Wood and Fiber Sci. 31: $416-425$.

Shelbourne, T., R. Evans, P. KibBlewhite and C. Low (1997): Inheritance of tracheid transverse dimensions and wood density in radiata pine. Appita 50: 47-50 and 67.

VARGAS-HeRnANDEZ, J. and W. T. ADAMS (1994): Genetic relationships between wood density components and cambial growth rhythm in young coastal Douglas-fir. Can. J. For. Res. 24: 1871-1876.

WANG, S. Y. and H. L. WANG (1999): Effects of moisture content and specific gravity on static bending properties and hardness of six wood species. J. Wood Sci. 45: 127-133.

Wang, T., S. N. Aitken, P. Rozenberg and F. Millie (2000): Selection for improved growth and wood density in lodgepole pine: effects on radial patterns of wood variation. Wood and Fiber Sci. 32: 391-403.

Yazdani, R., J.-E. Nilsson, C. Plomion and G. Mathur (2003): Marker trait association for autumn cold hardiness acclimation and growth rhythm in Pinus sylvestris. Scand. J. For. Res. 18: 29-38.

Zamudio, F., R. Baettyg, A. Vergara, F. Guerra and P. Rozenberg (2002): Genetic trends in wood density and radial growth with cambial age in a radiata pine progeny test. Ann. For. Sci. 59: 541-549.

ZHANG, S. Y. and Y. H. CHuI (1996): Selecting dry fiber weight for higher and better quality jack pine fiber production. Wood and Fiber Sci. 28: 146-152.

\section{Errata for following papers:}

1) Ginwal, H. S., P. S. Rawat and R. L. SRIvastava (2004): Seed source variation in growth performance and oil yield of Jatropha curcas Linn in central India. Silvae Genetica 53 (4): 186-192.

$\begin{array}{llll}\text { Page } & \text { Line/Table } & \text { Error } & \text { Correction } \\ 188 & \text { table 3 - first line } & \text { seed weight } & 10 \text { seed weight }\end{array}$

2) Ginwal, H. S., S. S. Phartyal, P. S. Rawat and R. L. SRivastava (2005): Seed source variation in morphology, germination and seedling growth of Jatropha curcas Linn in central India. Silvae Genetica 54 (2): 76-80.

$\begin{array}{ll}\text { Page } & \text { Line/Table } \\ 77 & 37 \\ 78 & 4 \text { (table } 2) \\ 78 & 5(\text { table } 2) \\ 78 & 6(\text { table } 2)\end{array}$

Error
100 seeds
100 whole seeds
100 seedcoat
100 kernel

Correction

10 seeds

10 whole seeds

10 seedcoat

10 kernel

Herausgeberin: Bundesforschungsanstalt für Forst- und Holzwirtschaft: Schriftleitung: Institut für Forstgenetik und Forstpflanzenzüchtung, Siekerlandstrasse 2, D-22927 Grosshansdorf — Verlag: J. D. Sauerländer's Verlag, Finkenhofstrasse 21, D-60322 Frankfurt a. M. Anzeigenverwaltung: J. D. Sauerländer's Verlag, Frankfurt am Main. Satz und Druck: ADN Offsetdruck, Battenberg - Printed in Germany. 